Supplement of

\title{
Determining the infrared radiative effects of Saharan dust: a radiative transfer modelling study based on vertically resolved measurements at Lampedusa
}

Daniela Meloni et al.

Correspondence to: Daniela Meloni (daniela.meloni@enea.it)

The copyright of individual parts of the supplement might differ from the CC BY 4.0 License. 
Table S1. Parameters (median radius, standard deviation and normalized number concentration) of the log-normal modes used to represent the observed in situ size distributions on F35 (top), F38 (middle) and F42 (bottom) for each layer as defined in the text. Parameters for the AERONET size distribution are also shown.

\begin{tabular}{l|l|cccc}
\hline F35 & & Mode 1 & Mode 2 & Mode 3 & Mode 4 \\
\hline LAYER 3 & $\mathrm{N}$ & 0.513428 & 0.394945 & 0.078989 & 0.012638 \\
& $\mathrm{R}(\mu \mathrm{m})$ & 0.039 & 0.070 & 0.200 & 0.775 \\
& Sigma & 1.28 & 1.50 & 1.55 & 2.18 \\
\hline LAYER 2 & $\mathrm{N}$ & 0.354811 & 0.638660 & 0.005677 & 0.000852 \\
& $\mathrm{R}(\mu \mathrm{m})$ & 0.039 & 0.070 & 0.185 & 0.650 \\
& Sigma & 1.28 & 1.50 & 1.55 & 2.18 \\
\hline LAYER 1 & $\mathrm{N}$ & 0.355771 & 0.640387 & 0.003558 & 0.000285 \\
& $\mathrm{R}(\mu \mathrm{m})$ & 0.045 & 0.070 & 0.140 & 0.675 \\
& Sigma & 1.50 & 1.50 & 1.55 & 2.80 \\
\hline AERONET & $\mathrm{N}$ & 0.936191 & 0.063372 & 0.000437 & n.a. \\
& $\mathrm{R}(\mu \mathrm{m})$ & 0.079 & 0.080 & 1.166 & n.a. \\
& Sigma & 1.38 & 2.57 & 1.59 & n.a. \\
\hline
\end{tabular}

\begin{tabular}{l|l|cccc}
\hline F38 & & Mode 1 & Mode 2 & Mode 3 & Mode 4 \\
\hline LAYER 2 & $\mathrm{N}$ & 0.542476 & 0.433981 & 0.021699 & 0.001844 \\
& $\mathrm{R}(\mu \mathrm{m})$ & 0.039 & 0.070 & 0.175 & 0.500 \\
& Sigma & 1.25 & 1.50 & 1.55 & 2.70 \\
\hline LAYER 1 & $\mathrm{N}$ & 0.791805 & 0.197951 & 0.009898 & 0.000346 \\
& $\mathrm{R}(\mu \mathrm{m})$ & 0.045 & 0.065 & 0.150 & 0.250 \\
& Sigma & 1.30 & 1.50 & 1.35 & 2.40 \\
\hline AERONET & $\mathrm{N}$ & 0.986421 & 0.013314 & 0.000265 & n.a. \\
& $\mathrm{R}(\mu \mathrm{m})$ & 0.083 & 0.250 & 1.487 & n.a. \\
& Sigma & 1.49 & 2.12 & 1.65 & n.a. \\
\hline
\end{tabular}




\begin{tabular}{l|l|cccc}
\hline F42 & & Mode 1 & Mode 2 & Mode 3 & Mode 4 \\
\hline LAYER 2 & $\mathrm{N}$ & 0.361011 & 0.577617 & 0.054152 & 0.007220 \\
& $\mathrm{R}(\mu \mathrm{m})$ & 0.040 & 0.060 & 0.185 & 0.800 \\
& Sigma & 1.25 & 1.50 & 1.55 & 1.80 \\
\hline LAYER 1 & $\mathrm{N}$ & 0.364742 & 0.607903 & 0.024316 & 0.003040 \\
& $\mathrm{R}(\mu \mathrm{m})$ & 0.035 & 0.055 & 0.165 & 0.450 \\
& Sigma & 1.25 & 1.50 & 1.55 & 2.50 \\
\hline AERONET & $\mathrm{N}$ & 0.965820 & 0.032717 & 0.001396 & 0.000067 \\
& $\mathrm{R}(\mu \mathrm{m})$ & 0.074 & 0.151 & 0.825 & 2.219 \\
& Sigma & 1.48 & 2.24 & 1.60 & 1.57 \\
\hline
\end{tabular}




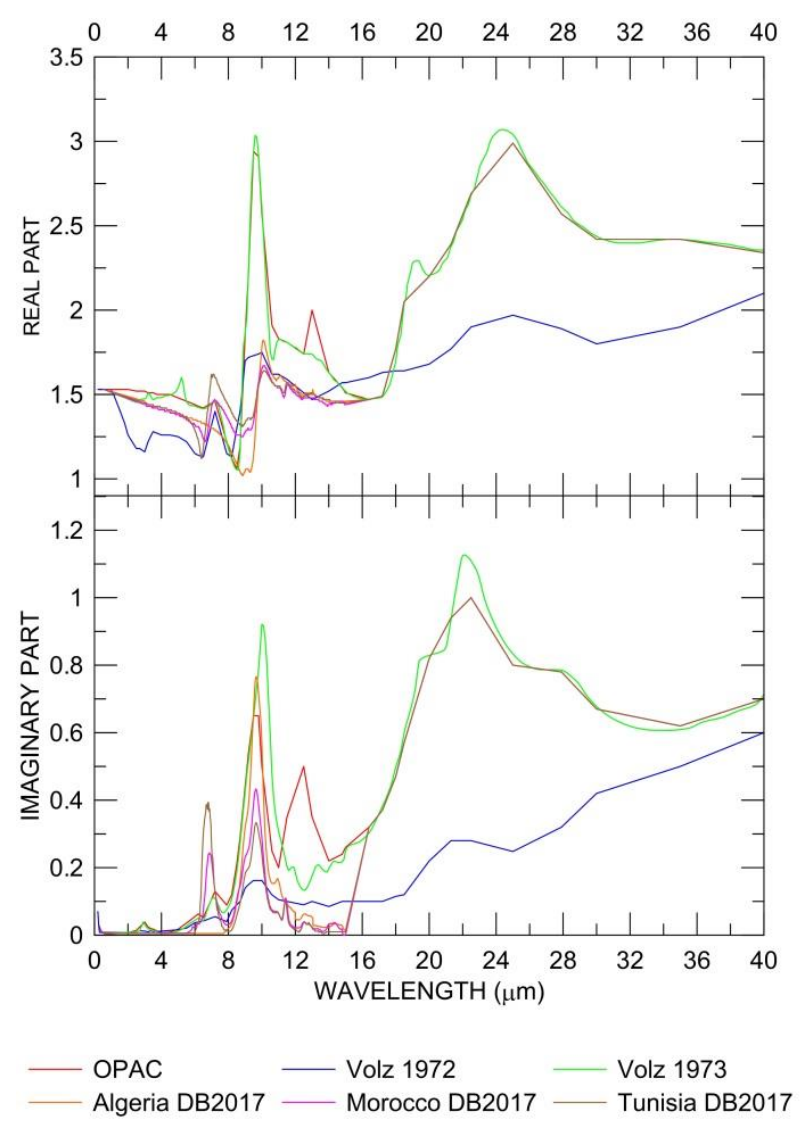

Figure S1. Dust spectral refractive indices used in the analysis, either from the most common literature (like OPAC, Volz 1972 and 1973), and from the most recent paper by Di Biagio et al. (2017) for the Algeria, Morocco and Tunisia source regions. 

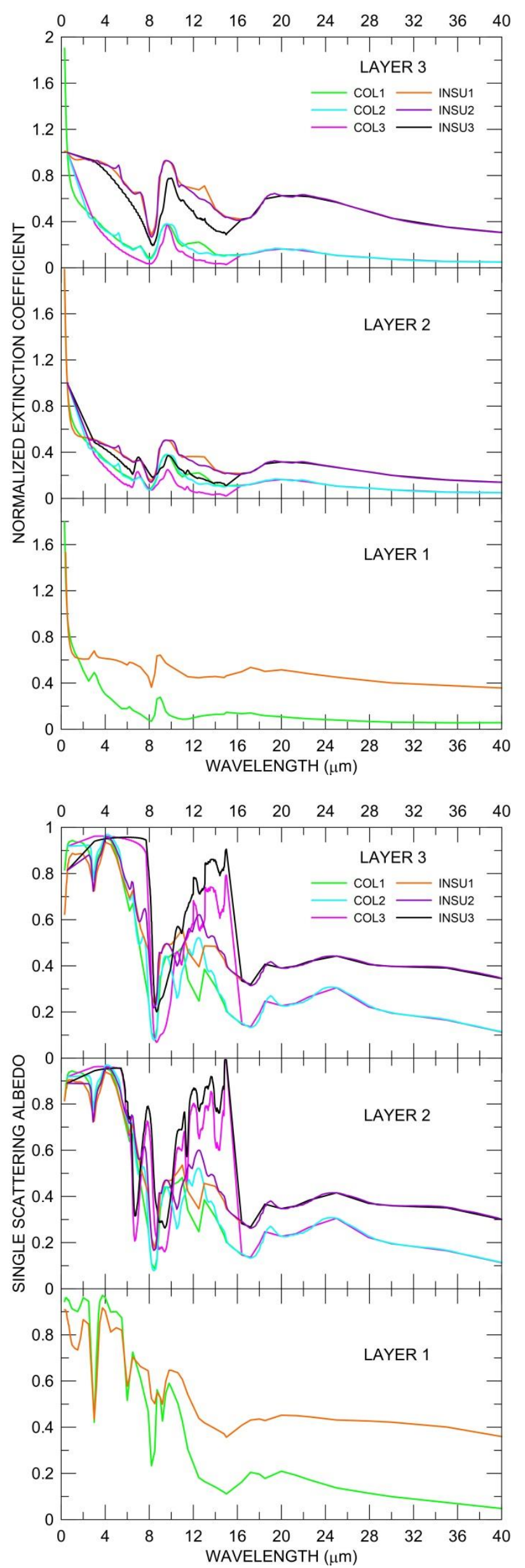


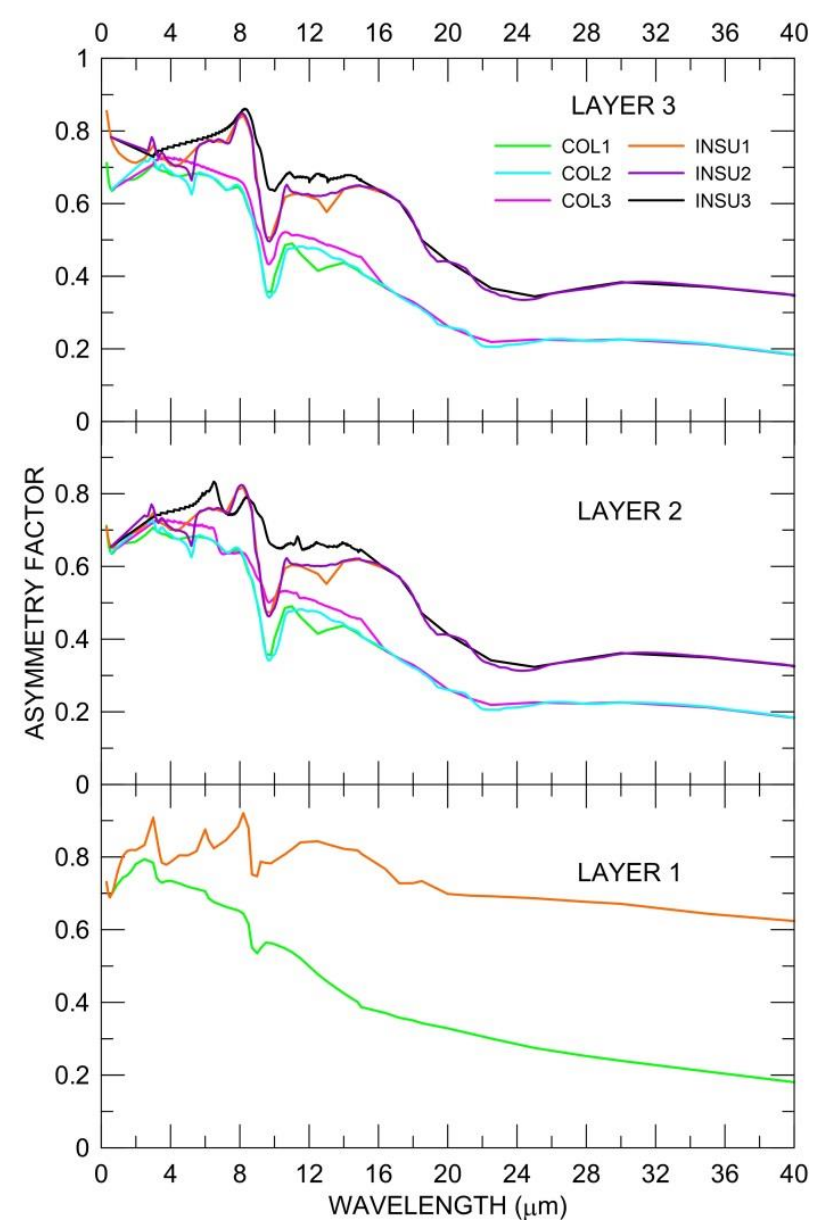

Figure S2. Extinction coefficients normalized to the value at $550 \mathrm{~nm}$ (upper plots), single scattering albedos (middle plots), and asymmetry factors (lower plots) in the 0-40 $\mu \mathrm{m}$ spectral interval computed with the Mie theory using the combination of SDs and RIs described in the text for each layer identified for the flight F35. Please note that COL1 and INSU1 AOPs in LAYER1 are calculated with the OPAC water soluble RI. 

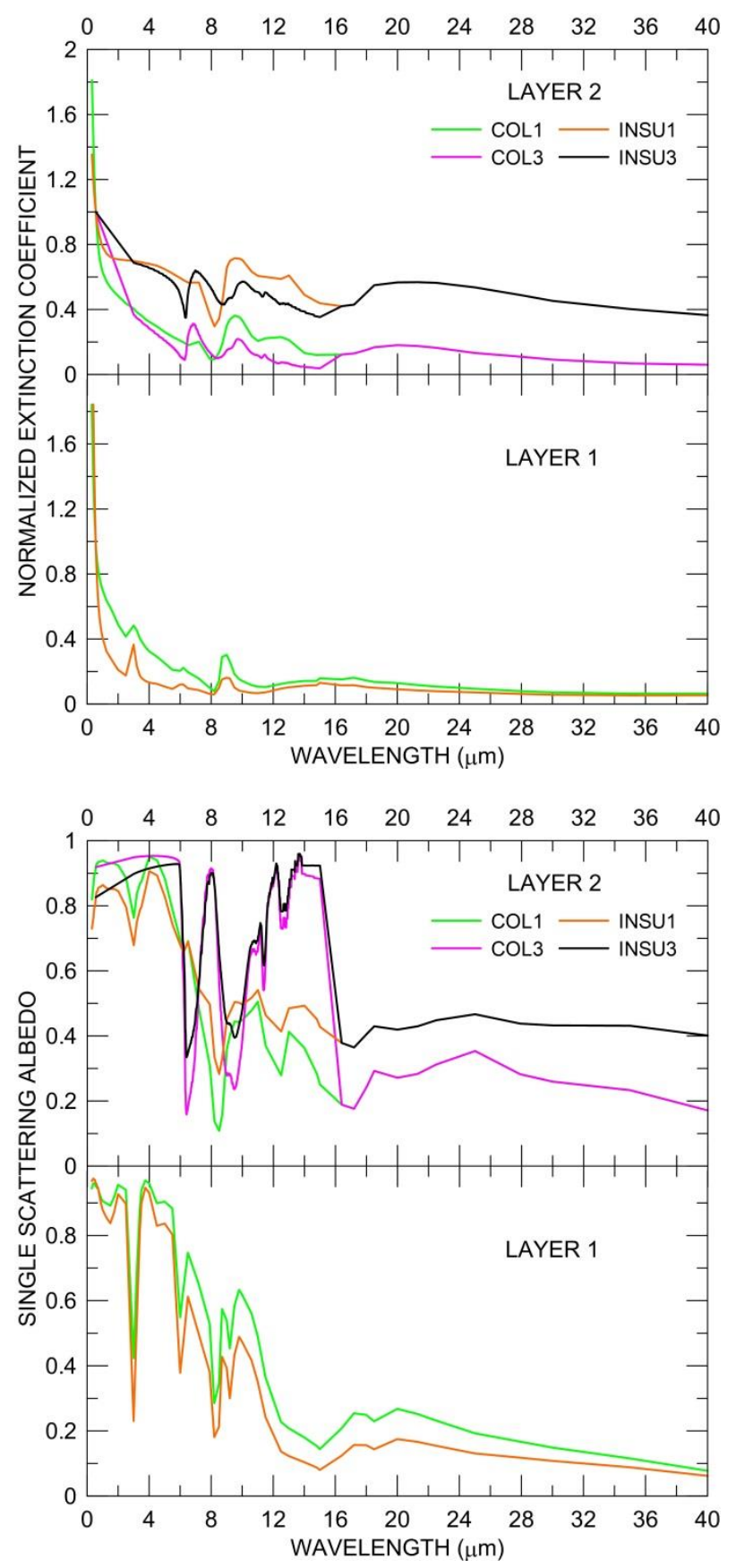


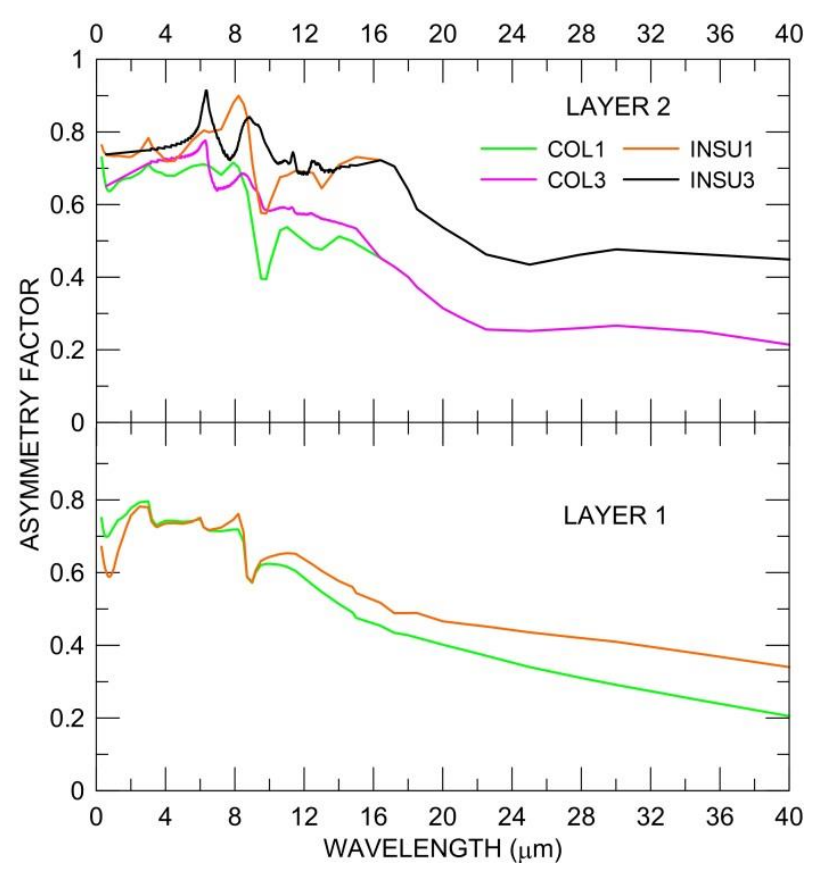

Figure S3. Same as Fig. S2, but for flight F38. 

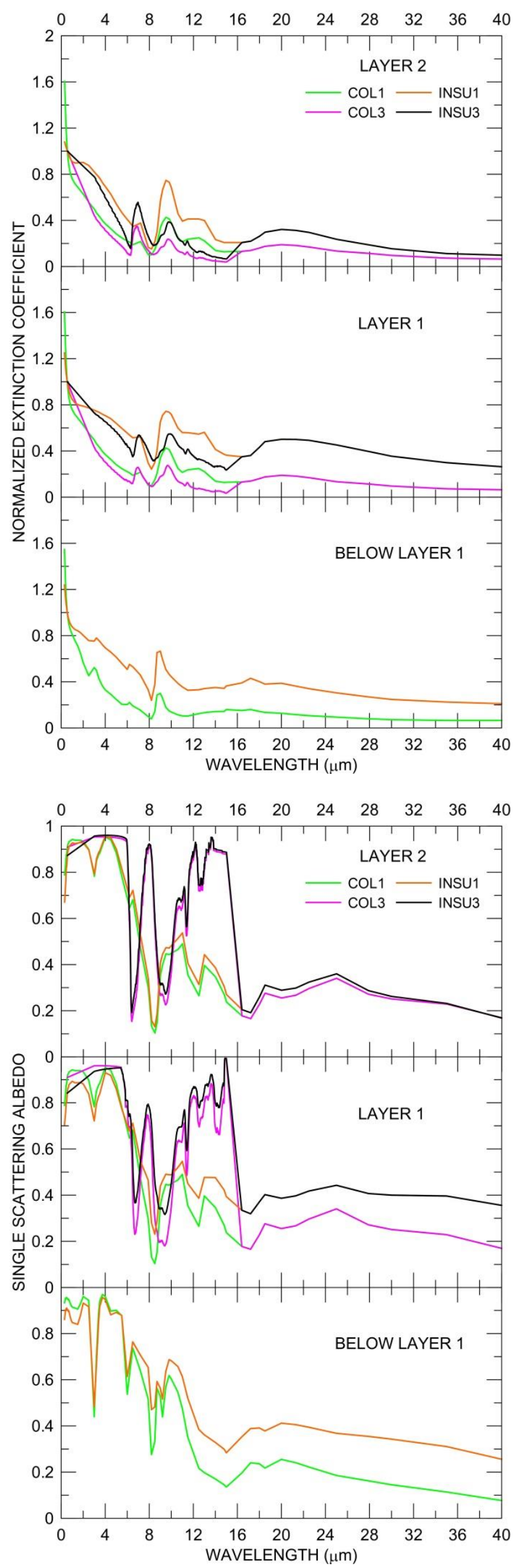


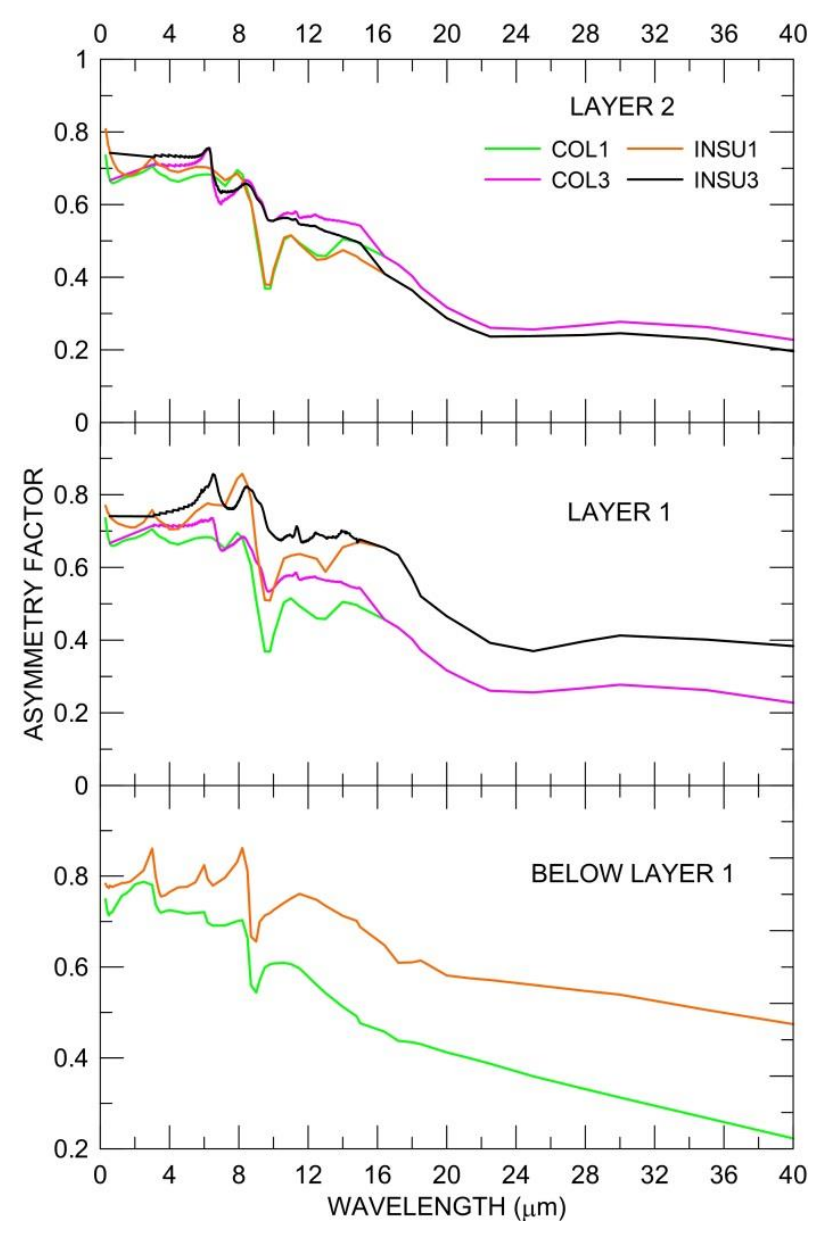

Figure S4. Same as Fig. S2, but for flight F42. 